\title{
BMJ Open What is the prevalence of and associations with forced labour experiences among male migrants from Dolakha, Nepal? Findings from a cross- sectional study of returnee migrants
}

Joelle Mak, ${ }^{1}$ Tanya Abramsky, ${ }^{1}$ Bandita Sijapati, ${ }^{2}$ Ligia Kiss, ${ }^{1}$ Cathy Zimmerman ${ }^{1}$

To cite: Mak J, Abramsky T, Sijapati B, et al. What is the prevalence of and associations with forced labour experiences among male migrants from Dolakha, Nepal? Findings from a cross-sectional study of returnee migrants. BMJ Open 2017;7:e015835. doi:10.1136/ bmjopen-2017-015835

- Prepublication history and additional material are available online. To view these files please visit the journal online (http://dx. doi.org/10.1136/bmjopen-2017015835).

Received 4 January 2017 Revised 21 April 2017 Accepted 1 June 2017

\section{CrossMark}

${ }^{1}$ Department of Global Health and Development, Faculty of Public Health and Policy, London School of Hygiene \& Tropical Medicine, London, UK

${ }^{2}$ Centre for the Study of Labour and Mobility, Social Science Baha, Kathmandu, Nepal

Correspondence to Dr Joelle Mak; joelle.mak@Ishtm.ac.uk

\section{ABSTRACT}

Objectives Growing numbers of people are migrating outside their country for work, and many experience precarious conditions, which have been linked to poor physical and mental health. While international dialogue on human trafficking, forced labour and slavery increases, prevalence data of such experiences remain limited. Methods Men from Dolakha, Nepal, who had ever migrated outside of Nepal for work were interviewed on their experiences, from predeparture to return $(n=194)$. Forced labour was assessed among those who returned within the past 10 years $(n=140)$ using the International Labour Organization's forced labour dimensions: (1) unfree recruitment; (2) work and life under duress; and (3) impossibility to leave employer. Forced labour is positive if any one of the dimensions is positive.

Results Participants had worked in India (34\%), Malaysia (34\%) and the Gulf Cooperation Council countries (29\%), working in factories $(29 \%)$, as labourers/porters $(15 \%)$ or in skilled employment (12\%). Among more recent returnees $(n=140), 44 \%$ experienced unfree recruitment, $71 \%$ work and life under duress and $14 \%$ impossibility to leave employer. Overall, $73 \%$ experienced forced labour during their most recent labour migration. Forced labour was more prevalent among those who had taken loans for their migration (PR 1.23) and slightly less prevalent among those who had migrated more than once (PR 0.87); however the proportion of those who experienced forced labour was still high (67\%). Age, destination and duration of stay were associated with only certain dimensions of forced labour. Conclusion Forced labour experiences were common during recruitment and at destination. Migrant workers need better advice on assessing agencies and brokers, and on accessing services at destinations. As labour migration from Nepal is not likely to reduce in the near future, interventions and policies at both source and destinations need to better address the challenges migrants face so they can achieve safer outcomes.

\section{INTRODUCTION}

Globally, increasing numbers of people are migrating for work. This has often been attributed to limited local employment opportunities, political instability,
Strengths and limitations of this study

- This study estimates the prevalence of forced labour using the International Labour Organization's forced labour measure, which was developed and tested in multiple countries. We applied this measure to a population sample of returnee labour migrants from Nepal to objectively quantify such experiences. This contributes to the evidence base in the field and allows for comparisons across different settings.

- A low response rate may have biased the results of the study and made the results less generalisable to the wider population of male labour migrants from the study region. All men from the study sites who had ever migrated outside of Nepal for work were eligible for inclusion in the study. However as repeat migration is common in this sample, only a small portion was located and interviewed.

- Although the forced labour measure combines a variety of indicators, the binary outcome remains problematic. Further research on how to conceptualise forced labour as a spectrum of experiences is needed.

- Due to the small sample size, this study did not have sufficient power to detect statistically significant associations with forced labour. It also precluded more complex multivariate analysis, adjustment for potential confounders or exploration of potential pathways of effect.

the demand for cheap labour and climate change, among others. ${ }^{1-3}$ Labour migration can be beneficial, with remittances contributing towards a range of household expenses, including education, healthcare or savings, which may be used as business start-up funds or to mitigate against crop failures. ${ }^{45}$ However, at the same time there is emerging recognition of the exploitation and abuses experienced by migrant workers in various countries and industries. ${ }^{6-9}$ Commonly reported experiences include 
contract breaches, limited freedom of movement, non-payment of wages and confiscation of identity documents. Outstanding debt or an absence of social network has been suggested as contributing factors that may increase migrants' vulnerability to experiences that are akin to forced labour, which the International Labour Organization (ILO) defines as: 'all work or service which is exacted from any person under the menace of any penalty and for which the said person has not offered himself voluntarily, ${ }^{6} 1011$

As evidence mounts on the far-reaching health and social consequences of such exploitations - including violence and mental health symptoms (depression, anxiety, post-traumatic stress or suicide attempts) ${ }^{12} 13$ - efforts to strengthen responses to forced labour and human trafficking have intensified. The Sustainable Development Goal 8.7 specifically aims to eradicate forced labour, modern slavery and human trafficking by 2030. Yet prevention efforts are hampered by evidence gaps, with notably few rigorous studies quantifying human trafficking and forced labour, ${ }^{14-16}$ in addition to terminological challenges, as forced labour, trafficking and slavery are applied somewhat interchangeably and measured inconsistently, making comparisons difficult. ${ }^{14-18}$

Labour migration is highly prevalent in Nepal. According to Nepal's 2011 census, one-quarter of households have at least one member absent or living abroad, and the World Bank suggests one-half of households have a current or ever-migrant. ${ }^{19} 20$ This paper reports labour migration experiences, including the extent and nature of forced labour experiences and associated factors, among a sample of Nepali male returnee migrant workers. Forced labour was used in this analysis due to the availability of guidelines and indicators to quantify such experiences. ${ }^{10}$

\section{METHODS}

\section{Study setting}

Nepal is a landlocked country sharing borders with India and China. Migration in Nepal is generally attributed to poverty, limited employment and livelihood opportunities ${ }^{2122}$; conflict ${ }^{23} 24$; and social networks..$^{22} 26$ Migration from Nepal to or via India is not officially recorded due to the open-border policy between the two countries. ${ }^{27}$ In 2014, nearly one-fifth of the remittances sent to Nepal came from India, which may be indicative of the numbers of Nepalis living in India. ${ }^{20}$ Apart from India, Nepali labour migrants commonly work in Malaysia and the Gulf Cooperation Council (GCC) countries, which include Qatar, Saudi Arabia, United Arab Emirates, Kuwait, Oman and Bahrain. Migrants primarily work in low-skilled jobs such as manufacturing and construction. ${ }^{9} 2028$ Studies and government reports suggest Nepali migrants often have limited understanding of their future work conditions and rights, and fatalities at destination have been increasing. ${ }^{20} 2930$ At the same time, labour migration has been credited with poverty reduction and contributes significantly to Nepal's economy, with official remittances steadily increasing since the 1990 s to represent over $30 \%$ of the gross domestic product in $2015 .^{720}$

This study uses data collected as part of the Study of Work in Freedom Transnational Evaluation to inform the ILO's Work in Freedom programme, which aims to reduce migrant workers' vulnerability to exploitation. The intervention runs in five districts in Nepal, including the study district, Dolakha. One ward in each of the three sites in Dolakha was selected: Bhimeshwar, the district municipality; Kavre, a periurban site; and Suri, a rural site.

\section{Sampling}

Sampling consisted of two phases. First, all households in the study sites were enumerated between February and April 2014. Household heads were interviewed to collect demographic and migration data for all household members. This process identified 444 men who had migrated outside of Nepal for work, and included 201 men who were away during the enumeration. In November 2014 we returned to locate and invite all returnee migrants to take part in the study by revisiting those homes. Up to three visits were conducted on different days and times to locate men, including making queries to the neighbours, in cases where houses appear to be unoccupied. Among the 444 men identified, 47 could not be located. Of the 397 located, $40.3 \%$ were abroad, $17.6 \%$ had relocated or were temporary away and $2.0 \%$ refused participation. Overall 159 men from the original sample were interviewed, resulting in a response rate of $40.1 \%$. A further 37 returnee men were identified who were not on our original roster. These men were included as we aimed to include all returnee men in the study sites (see details in online supplementary figure 1).

\section{Data collection}

A cross-sectional survey was designed to capture experiences throughout the migration cycle, including predeparture, travel, destination and return. Among men who had migrated for work more than once, the survey focused on their most recent migration. As eligible men included those who had returned from their migration many years ago, a shorter survey was designed for those who returned 10 or more years ago. The surveys were designed in English and translated into Nepali. The final English version was programmed into an electronic data collection software and then the Nepali translations pasted in. Data collection was conducted using tablets. Most questions on the survey included a 'not applicable' option and the programming was done to require a response to most questions to avoid missing data. A meeting was held with the fieldwork team each evening to discuss any issues and record any data that need correcting as the data collection application does not allow moving back after certain sections. 
Table 1 Dimensions and indicators of forced labour ${ }^{10}$

\section{Dimension of forced labour}

\begin{tabular}{|c|c|c|c|}
\hline \multirow[t]{9}{*}{ Unfree recruitment } & Involuntariness & Strong indicators & $\begin{array}{l}\text { Recruitment linked to debt (advance or loan) } \\
\text { Deception about the nature of the work }\end{array}$ \\
\hline & & Medium indicators & Deceptive recruitment \\
\hline & Penalty & Strong indicators & Denunciation to authorities \\
\hline & & & Confiscation of identity or travel documents \\
\hline & & & Sexual or physical violence \\
\hline & & & Withholding assets (cash or other) \\
\hline & & & Threats against family members \\
\hline & & Medium indicators & Exclusion from community and social life \\
\hline & & & Financial penalties \\
\hline \multirow{14}{*}{$\begin{array}{l}\text { Work and life under } \\
\text { duress }\end{array}$} & Involuntariness & Strong indicators & Forced overtime (beyond legal limit) \\
\hline & & & Limited freedom of movement and communication \\
\hline & & & Degrading living conditions \\
\hline & & Medium indicators & Multiple dependency on employer (housing) \\
\hline & Penalty & Strong indicators & Denunciation to authorities \\
\hline & & & Confiscation of identity or travel documents \\
\hline & & & Confiscation of mobile phone \\
\hline & & & Isolation \\
\hline & & & Locked in workplace/living quarters \\
\hline & & & Sexual/physical violence \\
\hline & & & Withholding assets (cash or other) \\
\hline & & & Threats against family members \\
\hline & & Medium indicators & Dismissal \\
\hline & & & Financial penalties \\
\hline \multirow{13}{*}{$\begin{array}{l}\text { Impossibility of } \\
\text { leaving employer }\end{array}$} & Involuntariness & Strong indicators & No freedom to resign \\
\hline & & & Forced to stay longer than agreed while waiting for wages due \\
\hline & & & $\begin{array}{l}\text { Forced to work for indeterminate period in order to repay } \\
\text { outstanding debt or wage advance }\end{array}$ \\
\hline & & Medium indicators & N/A \\
\hline & Penalty & Strong indicators & Denunciation to authorities \\
\hline & & & Confiscation of identity or travel documents \\
\hline & & & Locked in workplace/living quarters \\
\hline & & & Sexual/physical violence \\
\hline & & & Constant surveillance \\
\hline & & & Withholding of assets (cash or other) or of wages \\
\hline & & & Threats against family members \\
\hline & & Medium indicators & Dismissal \\
\hline & & & Financial penalties \\
\hline
\end{tabular}

\section{Measures}

Outcome

We used the ILO's forced labour measure, which includes three dimensions: (1) unfree recruitment; (2) work and life under duress; and (3) impossibility of leaving the employer. Within each dimension are indicators of involuntariness and penalty, further divided into strong and medium categories (table 1). Indicators were constructed from

\section{Indicator}

Recruitment linked to debt (advance or loan)

Deception about the nature of the work

Denunciation to authorities

Sexual or physical violence

Withholding assets (cash or other)

Financial penalties

Limited freedom of movement and communication

Degrading living conditions

Denunciation to authorities

Confiscation of identity or travel documents

Confiscation of mobile phone

Locked in workplace/living quarters

or other)

Dismissal

penalties

Forced to stay longer than agreed while waiting for wages due

Forced to work for indeterminate period in order to repay

Denunciation to authorities

Locked in workplace/living quarters

Sexual/physical violence

(cash or other) or of wages

Dismissal

Financial penalties

a group of variables (questions) asked in the survey in order to reduce bias, as individuals may define exploitation and forced labour differently from the ILO measure. Where indicators measured similar concepts (exclusion from social and community life, isolation, surveillance), these were checked to ensure that only one was counted as medium and strong indicators. Positive experience of a dimension is defined as at least one indicator of 
involuntariness and one of penalty within a dimension, of which one must be a strong indicator. Positive experience of any one of the three dimensions constitutes a positive experience of forced labour. ${ }^{10}$

\section{Exposures}

Three groups of exposure variables were explored: (1) demographics: age at departure of most recent migration, caste/ethnicity, education; (2) most recent migration destination and type of work; and (3) potential associated factors: debt (taken for the migration), social network (have contact with other migrants or contact information of migrant organisations), previous labour migration experience, attendance of training prior to departure, and awareness that agreed terms and conditions may be breached at destination.

\section{Ethics}

Ethical approval was obtained from the London School of Hygiene \& Tropical Medicine (7021) and the Nepal Health Research Council (1040). Fieldworkers received a 2-week training in Kathmandu conducted by JM that covered research ethics both for the safety of participants and fieldworkers, in addition to the specifics of the study, including the research design, instruments and procedures. Study participants were given study information verbally and in writing, and provided written consent before interviews began.

\section{Data analysis}

Data were analysed in Stata/SE V.14. Descriptive statistics are presented on sociodemographics and labour migration history. Prevalence of the three dimensions of forced labour and forced labour itself was calculated only among men who returned from their most recent migration within the past 10 years $(\mathrm{n}=140)$ as these individuals had completed the long survey and could be used in the analysis for forced labour experiences. Men who had returned from their most recent migration 10 or more years ago completed a shorter survey which did not have sufficient data to estimate forced labour. The proportion of participants who experienced each indicator is presented separately for those who worked in India versus other destinations due to the open-border policy and sociolinguistic similarities between the two countries, which may affect forced labour experiences. Bivariate analysis between exposure variables and the dimensions of forced labour is presented with $\mathrm{X}^{2}$ or Fisher's exact tests of association. Lastly, log-binomial regression was used to estimate the association (prevalence ratio (PR) and 95\% CIs). When examining forced labour by destination, India was also excluded for the same reasons mentioned previously. Exposure categories were collapsed where fewer than $5 \%$ of participants reported data within one stratum.

\section{RESULTS}

\section{Description of study sample}

The characteristics of the 194 male participants are presented in table 2. Over half were under 40 years old at the time of interview (55\%). Approximately $35 \%$ were of the Chhetree ethnic/caste group (an 'upper caste' group), and one-quarter were Janajatis, the indigenous groups. The vast majority were married $(89 \%)$ and had attended some secondary school $(40 \%)$, while $17 \%$ had never attended school or only had informal education. Most participants spoke Nepali as their main language (83\%) and $79 \%$ also spoke Hindi. Nearly $42 \%$ spoke English, 23\% Malay and 18\% Arabic, languages of common destinations.

\section{First labour migration experience}

Most participants (62\%) had only migrated for work outside of Nepal once. Among those who had migrated more than once, most had gone two to three times, while $6 \%$ had gone four or more times (table 3). Over half of the men $(57 \%)$ left for their very first labour migration between the ages of 18 and 29, and $4 \%$ left when they were aged 40 or older.

\section{Most recent labour migration experience}

During their most recent migration, nearly half stayed in the destination country for over 3 years, while $13 \%$ stayed for less than 1 year. The majority of participants $(67 \%)$ were under the age of 30 when they left Nepal for their most recent migration, with $11 \%$ under the age of 18 .

Common destinations were India and Malaysia (34\% each), followed by the GCC countries (29\%). A small number of men worked in other countries: China, South Korea, Bhutan and Iraq. Most often, men worked in factories $(29 \%)$, as general labourer/porter $(15 \%)$, and $12 \%$ worked in more skilled employment (eg, accountant, mechanic, engineer) (table 3).

\section{Prevalence of forced labour dimensions}

Most men who returned from their most recent labour migration within the past 10 years $(n=140)$ experienced exploitation at all stages of the migration process (table 4). Half reported deceptive recruitment in which the employment conditions such as wages, location, employer, duration, or living and working situations differed from what they were told before leaving Nepal, and $19 \%$ reported the actual job was different. Debtlinked recruitment, however, was rare, with very few men reporting their employer at destination or agent in Nepal had provided loans or advances which had to be repaid from their salary at destination.

Forty-five per cent reported limited freedom of movement or communication at destination, which included being unable to speak to anyone they wanted over the phone, to leave the work premises or go out unaccompanied during non-working hours, or to have their phones or address books confiscated, and 91\% depended on their employer for housing. Over one-quarter reported having worked overtime without additional pay. Conversely, very few reported not being able to resign, and none reported being forced to stay due to outstanding debts. 
Table 2 Sociodemographic characteristics by site, $\mathrm{n}$ (\%), $n=194$

\begin{tabular}{|c|c|}
\hline & Total $(n=194)$ \\
\hline \multicolumn{2}{|l|}{ Age groups } \\
\hline $18-29$ & $46(23.7)$ \\
\hline 30-39 & $61(31.4)$ \\
\hline $40-49$ & $26(13.4)$ \\
\hline $50-59$ & 25 (12.9) \\
\hline$\geq 60$ & $36(18.6)$ \\
\hline Median (IQR) & $37(30-52)$ \\
\hline \multicolumn{2}{|l|}{ Caste/ethnicity } \\
\hline Chhetree & 69 (35.6) \\
\hline Brahman-Hill & $35(18.0)$ \\
\hline Newar & $35(18.0)$ \\
\hline Janajati & $47(24.2)$ \\
\hline Other (Dalit, Muslim) & $8(4.1)$ \\
\hline \multicolumn{2}{|l|}{ Current marital status } \\
\hline Unmarried & $18(9.3)$ \\
\hline Married/polymarried & $173(89.2)$ \\
\hline Separated/divorced/widowed & $3(1.6)$ \\
\hline \multicolumn{2}{|l|}{ Highest level of education attended } \\
\hline None/informal & $33(17.0)$ \\
\hline Primary & $52(26.8)$ \\
\hline Secondary & $78(40.2)$ \\
\hline Higher secondary/vocational/tertiary & $31(16.0)$ \\
\hline \multicolumn{2}{|l|}{ Main language spoken } \\
\hline Nepali & $160(82.5)$ \\
\hline Thami & $17(8.8)$ \\
\hline Tamang & $10(5.2)$ \\
\hline Other & $7(3.6)$ \\
\hline \multicolumn{2}{|l|}{ Other languages spoken (multiple options allowed) } \\
\hline Hindi & $153(78.9)$ \\
\hline English & $81(41.8)$ \\
\hline Malay & $44(22.7)$ \\
\hline Nepali & $34(17.5)$ \\
\hline Arabic & $34(17.5)$ \\
\hline Newari & $11(5.7)$ \\
\hline Tamang & $8(4.1)$ \\
\hline Bengali & $6(3.1)$ \\
\hline Thami & $4(2.1)$ \\
\hline Sherpa & $4(2.1)$ \\
\hline Other & $14(7.2)$ \\
\hline No other languages spoken & $11(9.3)$ \\
\hline Median number of other languages spoken (IQR) & $2(1-3)$ \\
\hline \multicolumn{2}{|l|}{ Ability to read (in any language) } \\
\hline No & $16(8.2)$ \\
\hline With much difficulty & $12(6.2)$ \\
\hline With some difficulty & $31(16.0)$ \\
\hline Fluently & $135(69.6)$ \\
\hline
\end{tabular}

Continued
Table 2 Continued

\begin{tabular}{ll}
\hline \multicolumn{2}{l}{ Total $(\mathbf{n}=\mathbf{1 9 4})$} \\
\hline None & \\
\hline 1 & $6(3.4)$ \\
$2-4$ & $32(18.3)$ \\
$\geq 5$ & $111(63.4)$ \\
Median (IQR) & $26(14.9)$ \\
\hline
\end{tabular}

Over half the participants reported having their identity documents confiscated with no possibility of getting them back if needed (52\%); $44 \%$ reported isolation, which includes elements of being excluded from community and social life, or being under surveillance. One-third experienced financial penalties such as having wages deducted as punishment or while on sick leave, or being threatened with non-payment of wages. Additionally, 27\% reported having assets (ie, mobile phone, address book, wages) withheld.

Among those who worked in India in their most recent migration, over half were forced to work overtime without pay, and just under half (45\%) had some of their assets withheld, or restrictions of movement or communication. Very few experienced unfree recruitment or impossibility of leaving employer, while $55 \%$ experienced work and life under duress and forced labour.

Overall, in their most recent labour migration, $44 \%$ of participants experienced unfree recruitment, $71 \%$ for work and life under duress and $14 \%$ for impossibility of leaving employer. Experience of any of the three dimensions constituted experience of forced labour, and $73 \%$ of the participants were thus classified.

\section{Factors associated with forced labour}

Demographic and key exposures were examined in relation to each of the dimensions, and to the overall forced labour outcome. For most exposures, similar PRs were observed. While men who had migrated for work more than once had a lower prevalence of forced labour (PR $0.87,95 \%$ CI 0.70 to 1.09 ) compared with those who had migrated only once, nearly $67 \%$ of those with repeat migrations still experienced forced labour during their most recent migration (table 5). There was some suggestion that men who had taken out loans for their migration experienced a higher PR for forced labour, although the associations were only statistically significant with the unfree recruitment dimension: PR 1.67 (95\% CI 1.00 to 2.79) for unfree recruitment; PR 1.18 (95\% CI 0.91 to 1.55$)$ for work and life under duress; PR $1.12(95 \%$ CI 0.43 to 2.91) for impossibility to leave employer, and PR 1.23 (95\% CI 0.95 to 1.60 ) for the overall forced labour. Those who had attended trainings before leaving Nepal had a higher prevalence of all three dimensions as well as of forced labour: PR 1.24 (95\% CI 0.72 to 2.14) for unfree recruitment; PR 1.15 (95\% CI 0.30 to 4.45 ) for impossibility to leave; PR 1.35 (95\% CI 1.11 to 1.64) for work and life 
Table 3 Labour migration histories and characteristics of most recent migration, $\mathrm{n}(\%), \mathrm{n}=194$

Total $(n=194)$

\begin{tabular}{ll}
$\begin{array}{l}\text { Labour migration history } \\
\text { Number of labour migration experiences }\end{array}$ \\
\hline 1 & $120(61.9)$ \\
$2-3$ & $63(32.5)$ \\
$\geq 4$ & $11(5.7)$ \\
Median (IQR) & $1(1-2)$
\end{tabular}

Age at first labour migration

$\begin{array}{ll}<18 & 44(22.7) \\ 18-29 & 111(57.2) \\ 30-39 & 31(16.0) \\ \geq 40 & 8(4.1) \\ \text { Median (IQR) } & 22(18-27)\end{array}$

Marital status at first labour migration

$\begin{array}{ll}\text { Unmarried } & 100(51.6) \\ \text { Married } & 94(48.5)\end{array}$

Most recent labour migration

Duration of stay*

\begin{tabular}{|ll}
\hline$<1$ year & $24(12.7)$ \\
\hline 1-3years & $74(39.2)$ \\
\hline 3years & $91(48.2)$ \\
\hline Median in months (IQR) & $34(18-60)$ \\
\hline $\begin{array}{l}\text { Age groups (at departure of most recent } \\
\text { labour migration) }\end{array}$ & \\
\hline$<18$ & $21(10.8)$ \\
\hline $18-29$ & $108(55.7)$ \\
\hline $30-39$ & $38(19.6)$ \\
\hline$\geq 40$ & $27(13.9)$ \\
\hline Median (IQR) & $25(20-31.5)$ \\
\hline Most recent migration destination & \\
\hline India & $66(34.0)$ \\
\hline Malaysia & $65(33.5)$ \\
\hline Gulf states (Qatar, Saudi Arabia, United & $56(28.9)$ \\
\hline Arab Emirates, Kuwait, Oman, Bahrain) & \\
\hline Others (Iraq, Bhutan, China, South Korea) & $7(3.6)$ \\
\hline Most recent migration work & \\
\hline Construction worker & $18(9.3)$ \\
\hline Factory worker & $56(29.0)$ \\
\hline Kitchen/food-related work & $16(8.3)$ \\
\hline Security & $14(7.3)$ \\
\hline General labour/helper & $29(15.0)$ \\
\hline Supervisor or other skilled $†$ & $24(12.4)$ \\
\hline Otherf & $36(18.7)$ \\
\hline
\end{tabular}

*Missing duration of stay for five men who did not remember which year they left or returned to Nepal.

†Includes supervisors, accountant, mechanic, engineer, electrician, priest.

‡Cleaner, agriculture workers, laundry workers. under duress; and PR 1.30 (95\% CI 1.07 to 1.58) for forced labour, with the latter two outcomes reaching statistical significance.

Several exposures appear to be associated with only certain dimensions of forced labour, including age, destination, duration of stay and awareness of agreement breach potentials. Men who were older when they left Nepal had a lower prevalence of the impossibility to leave employer dimension compared with younger men: PR 0.79 (95\% CI 0.32 to 1.99) for those aged 25-34 and 0.64 (95\% CI 0.15 to 2.75) for those over 34, compared with those under 25. But age group was not associated with the other two dimensions. Men who worked in the GCC countries were more likely to experience impossibility to leave employer (PR 1.38 (95\% CI: 0.54 to 3.58)) compared with those who worked in Malaysia, while for the other dimensions and for forced labour, similar PRs were observed between the two destinations. Compared with men who stayed in the destination country for less than 1 year, men who remained longer were more likely to have experienced unfree recruitment (PR 1.59 (95\% CI 0.67 to 3.78) for stays between 1 and 3 years; and PR 1.34 (95\% CI 0.56 to 3.18) for stays of over 3 years). For men who stayed between 1 and 3 years, the PR for work and life under duress was 1.37 (95\% CI 0.80 to 2.32) and 1.28 (95\% CI 0.76 to 2.18) for those who stayed longer. Conversely, longer stays appear to be associated with lower prevalence of the impossibility to leave employer dimension (PR 0.25 (95\% CI: 0.06 to 1.01)) for stays of over 3 years compared with stays for less than 1 year, although some categories had very few men. Men who returned from their most recent migration between 5 and 10 years ago had a lower PR of unfree recruitment (PR $0.80,95 \%$ CI 0.48 to 1.34 ) compared with men who returned within the past 12 months, while the reverse was observed for impossibility to leave employer, where those who returned between 5 and 10 years ago had a higher prevalence (PR 2.06, 95\% CI 0.56 to 7.61) compared with those who returned within the past 12 months. Men who were aware of agreement breaches potentials at destination had higher prevalence of unfree recruitment (PR 2.23 (95\% CI 1.07 to 4.64)) than those who said they were unaware prior to leaving. However, this was not associated with the other dimensions of forced labour.

\section{DISCUSSION}

This paper offers findings about the prevalence of and factors associated with different dimensions of forced labour among a general population of male Nepali migrant workers using the ILO measures. Previous studies in Nepal have been primarily qualitative, and shed light on the nature and experiences of exploitation particularly in relation to child labour ${ }^{3132}$ and bonded labour. ${ }^{3233}$ Our results indicate that $73 \%$ of returnee migrants had experienced forced labour at their most recent labour migration. This appears to be similar to figures noted in a study conducted by Verité on workers in the electronic sector in Malaysia using the ILO measures (66\%) when 


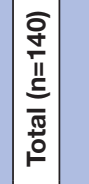

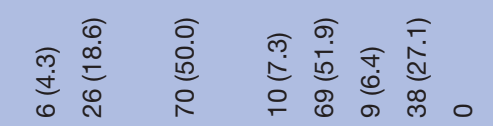

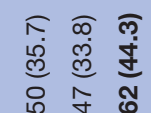

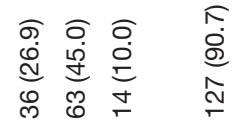

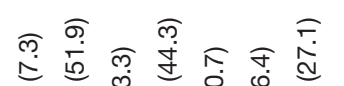

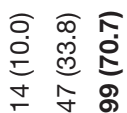

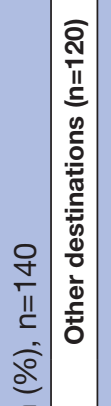

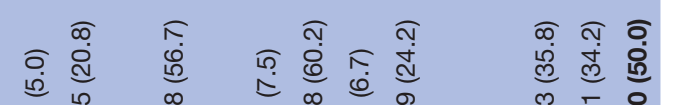

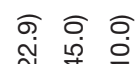

$\underset{\substack{\infty \\ \infty \\ \infty}}{\infty}$

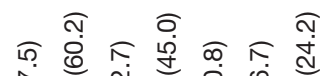

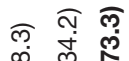

ล

陮

으 ᄃ

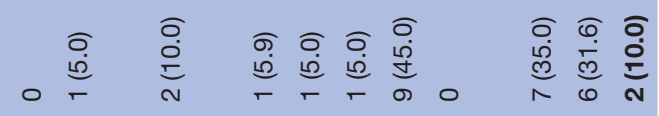

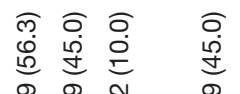

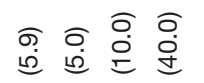

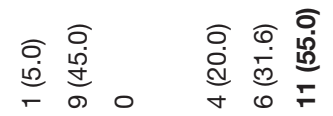




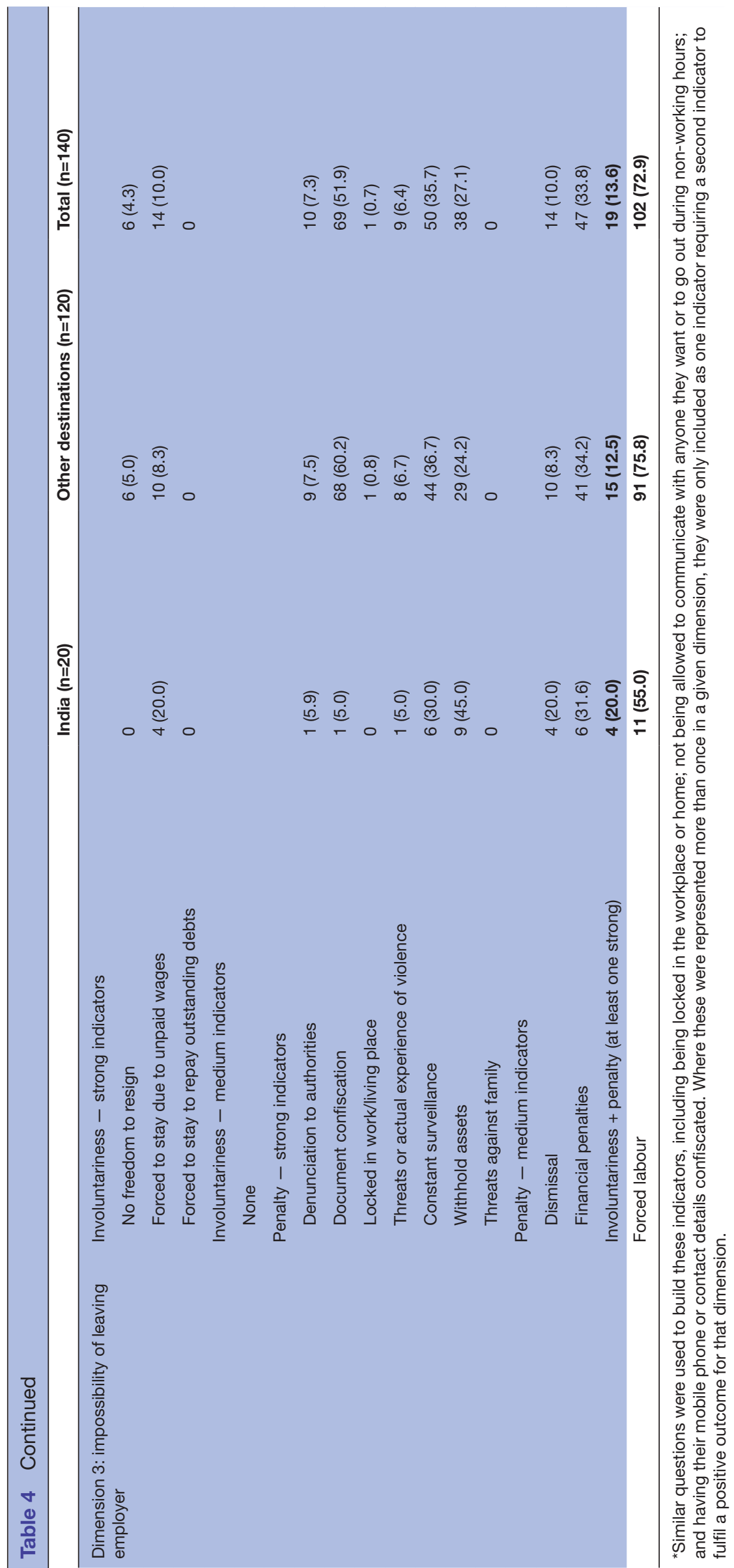

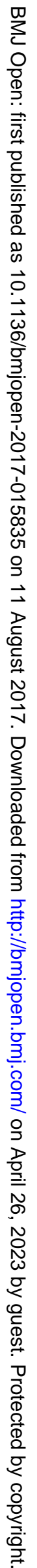




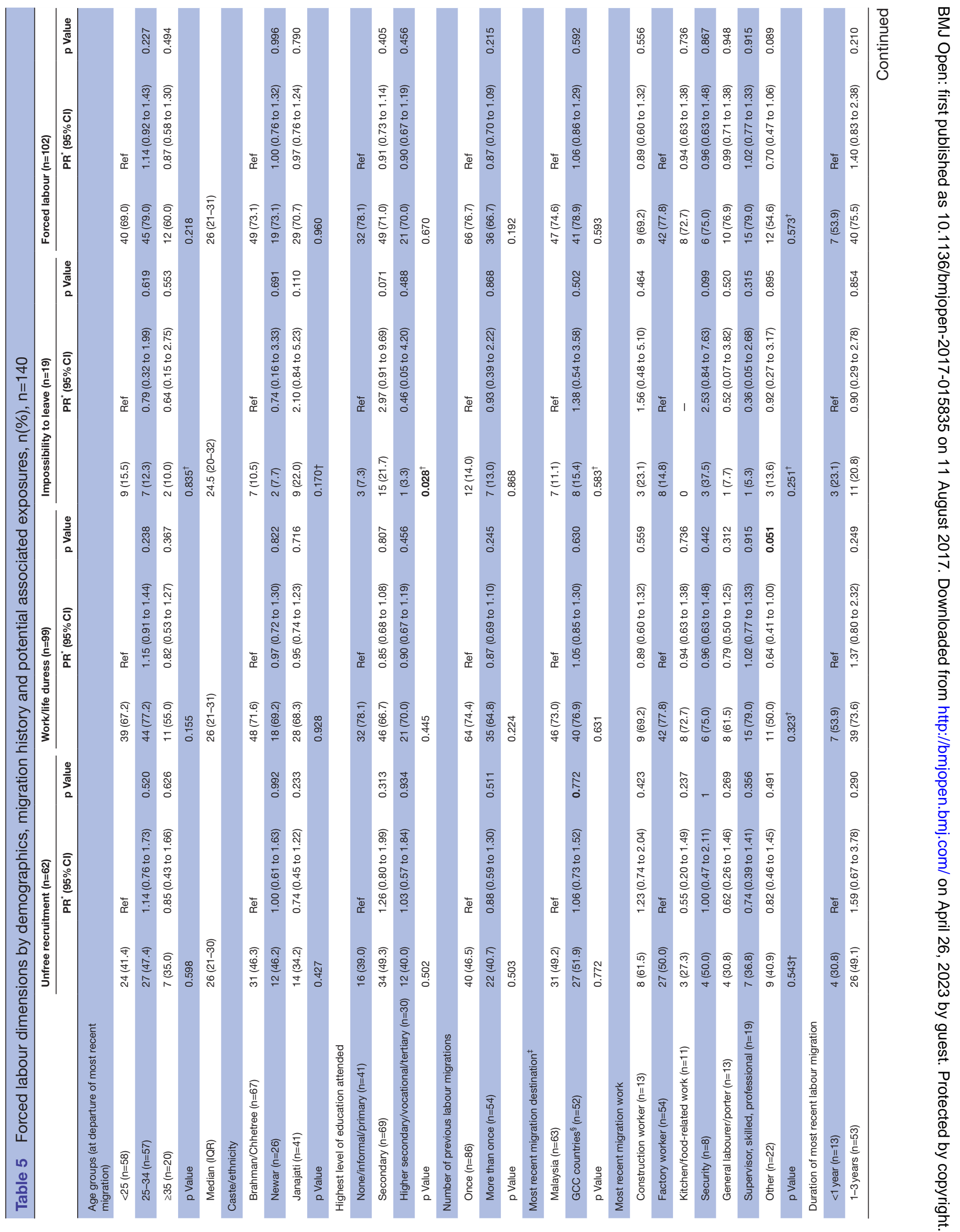




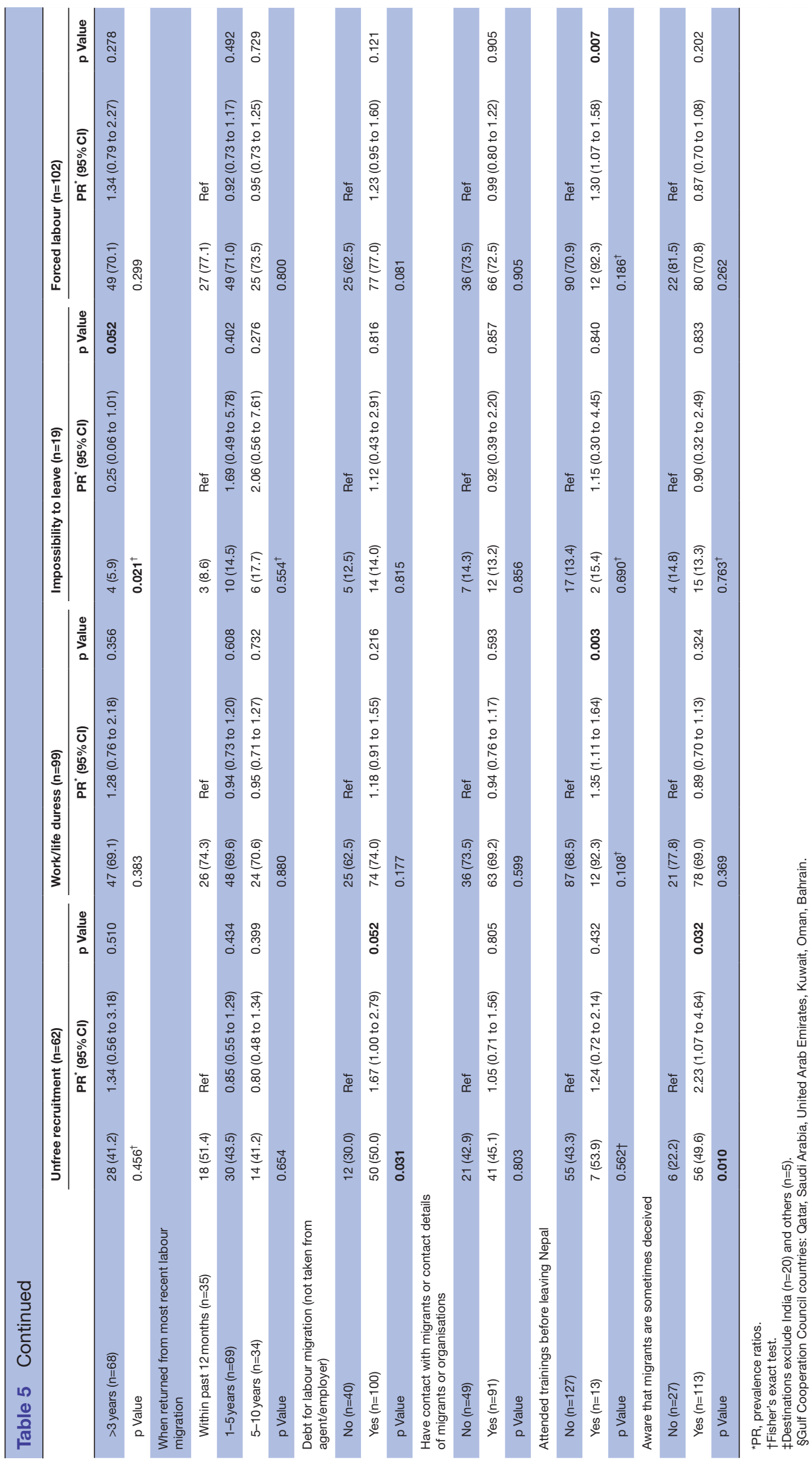

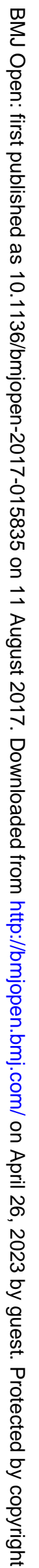


the indicator 'confiscation of passport' was included (which was not in the overall estimates). ${ }^{34}$ Similar types of exploitations were reported by Amnesty International's qualitative research with returnees identified as having had problems with their migration, ${ }^{29}$ while a small study by The Asia Foundation ${ }^{6}$ identified a range of problems at destination reported by returnee men and women that included salary discrepancies, contract substitutions, as well as food and relationships with others. Additionally, many migrants who reported that they were satisfied with their work conditions had experienced some violation of their rights, indicating the need to have a comparable measure. ${ }^{35}$ While prevalence estimates by sector are still limited, other studies on migrant workers and exploitation in many low-wage labour sectors, both formal and informal around the world, have shown similar types of issues, indicating the embedded nature of these global practices in pursuit of low-cost goods and services. ${ }^{36}$ Further research using comparable measures and disaggregated by sector would be a welcome addition to this field.

It is clear that 'forced labour' is not a single act; rather, it generally comprised multiple abuses by multiple actors, which indicates the profound challenges involved in developing interventions. For example, over $44 \%$ of men in our analysis reported unfree recruitment, including deceptive recruitment, suggesting practical information and guidance are needed so prospective migrant workers can assess recruiters and agencies, employment agreement terms and conditions, and to be informed of their legal rights and strategies for redress, particularly once at destination. Other studies have linked recruitment practices to subsequent exploitations, ${ }^{29} 37$ while others have highlighted the important role brokers play and the need to involve them in safer migration strategies. ${ }^{38}$ Many workers at destination experienced restrictions in their movements and communication and were almost always dependent on their employer for housing. Therefore, programmes should consider interventions that do not solely rely on migrant workers' ability to seek help at destination. Further development and use of mobile technology could be an option, given that very few participants reported having their phones confiscated and data from our household census indicate that nearly all migrants stayed in touch using mobile phones.

Nepal has introduced various policies and governmental entities to promote and regulate labour migration. ${ }^{39} 40$ Most of these mechanisms are focused on managing the migration process, while protection for workers, particularly once abroad, is lacking despite the inclusion on provisions of redress in some bilateral agreements. ${ }^{41}$ Greater advocacy is also needed to lobby destination countries to respect the rights of migrant workers.

Our results indicate that previous experience of labour migration may not be as protective of future forced labour experiences as hypothesised. Although a lower PR of forced labour was found among those who had migrated more than once, $67 \%$ of those still reported forced labour during their most recent labour migration. Previous migration may have shaped men's views on the process and how they assess their experiences, which may have impacted how they responded to certain questions. Although forced labour was determined using a large number of questions on their actual experiences, rather than perceptions, this should not have altered the results too much. This indicates that interventions need to target both experienced and first-time labour migrants. However, experienced migrants may not recognise the benefits of participating, possibly believing that their prior experience offers sufficient protection. They may also normalised their experiences as the realities of labour migration rather than a violation of their rights. Interventions may have to reach out differently to these two groups. Interventions that make use of returnee migrants to offer guidance to other prospective migrants should also recognise that simply being returnees may be insufficient, particularly with the changing labour migration regulations in Nepal.

Many Nepali migrant workers do not consider India as a destination due to the two countries' open-border policy that ensures citizens of both countries are given equal rights to move, live and work freely without specific documentation in either country. ${ }^{27}$ Our findings did indicate that forced labour was lower among men who worked in India and that those experiences were largely in destination.

Our findings confirm previous research that debt increases vulnerability to forced labour. Excessively high fees charged by recruitment agencies and agents may lead prospective migrants to take out loans at far higher interest rates, resulting in them staying in jobs with exploitative conditions until the debts are repaid. ${ }^{6} 1129$ Furthermore, if men had taken loans to fund their migration and only learnt of the actual job and conditions after arrival at destination, returning home empty-handed and in debt may not be a realistic option for many. Our results indicate that longer stays are associated with higher prevalence of forced labour, which may also be related to the increased pressure to repay debts. ${ }^{42}$ Current policies aimed at restricting the costs to prospective migrants and initiatives such as 'free ticket free visa' may help protect migrants from such exploitations. ${ }^{43}$

Somewhat surprisingly, men who reported that they were aware of the possibility of agreement breaches had a slightly higher prevalence of forced labour than those who reported being unaware. Recall bias and reverse causality are possible explanations. Although we phrased the question to ask about awareness prior to leaving Nepal, it is possible men reported current awareness resulting, in part, from their experience.

Precarious labour conditions, where workers have little or no security, low wages, little power or agency, have been linked to poor physical and mental health outcomes. ${ }^{44}$ Such working conditions are typical of migrant workers in our sample. Health protections and medical services for migrant workers must be provided in both destination 
and return settings in order for migrant workers to maintain their health and well-being and future capacity to work.

\section{Limitations}

Recall bias, particularly among men who returned to Nepal many years ago, is a concern. To minimise the potential influence, a shorter questionnaire was used among men who returned over 10 years ago, excluding, among other things, a number of indicators that make up the forced labour measure. As a consequence, the sample that could be used to estimate the prevalence of forced labour was reduced by one-quarter. Due to the small sample size, this study had low power to detect statistically significant associations. It is therefore difficult to draw conclusive results about exposures where data were suggestive of an association but CIs were wide. It also precluded more complex multivariate analysis, adjustment for potential confounders or exploration of potential pathways of effect, which had been the original intent. Nevertheless, important observations on the scale of forced labour experiences were made, and potential factors were identified that would be worthy of further investigation. Further research, using larger samples, is needed to better understand the relationships observed.

It is difficult to capture the true prevalence of forced labour using the ILO measure itself as those who have not returned to Nepal may include those who have done well and continue their stay and those who have experienced the worst forms of exploitation and could not make it back. The latter has been highlighted by the increasing numbers of migrant worker fatalities at destination. ${ }^{20}$ Additionally those who do return to their village of origins and are included in our study are likely to be different from those who relocated to another part of Nepal. This affects the generalisability of study results they provide an estimate of experience of forced labour among male returnees to study regions rather than one that is generalisable to all male migrants from these regions. Nevertheless study results are useful to gauge the extent of forced labour, explore correlates with forced labour and help plan services for the population of returnees.

A further limitation affecting the generalisability of study results is the relatively low response rate to the survey, a common issue in studies of mobile populations. Although intended to be representative of all male returnee labour migrants from the study sites, over $40 \%$ of the original men identified in the enumeration were abroad during fieldwork and were thus not interviewed. As a result, our sample likely disproportionately excludes migrants who migrate multiple times. Since tendency to remigrate might be directly affected by experiences during prior migrations, our prevalence estimate may be biased upwards, for example, where past bad experiences mean repeat migration is necessary to pay off outstanding debts.

The binary measure of forced labour itself would be better conceptualised as a spectrum of experiences.
Although it is widely recognised that exploitation happens along a continuum, with 'decent work' at one end and 'forced labour' at the other, there is little consensus on when exploitation becomes forced labour, making measurement challenging. ${ }^{42} 4546$ The ILO measure is nevertheless helpful in disaggregating the different exploitative experiences separately from the binary outcome.

\section{CONCLUSION}

The fact that large numbers of Nepali labour migrants experienced forced labour across a variety of destinations and work sectors indicates the widespread nature of migration-related and labour-related abuses. Until there are shifts in the structural factors that underpin these exploitations, migrant workers need better advice and guidance on how to assess recruitment agencies and brokers, and how to access services at destinations. Interventions need to consider the potential restrictive realities of migrant workers. Simultaneously, states that employ migrant workforce need to become more aware of and establish measures to prevent and punish the tactics used to exploit workers. Further research should disaggregate exploitative experiences by sector, as well as assess the strength and direction of the associated factors, accounting for confounders and mediators. As labour migration from Nepal is not likely to reduce in the near future, interventions need to better address the challenges prospective migrants face and help them achieve safer migration and health outcomes.

Acknowledgements The authors would like to thank all the study participants for sharing their experiences. They would also like to thank Michaelle De Cock for advice on the forced labour indicators, Isolde Birdthistle for data analysis advice, Amrita Limbu for coordinating the fieldwork, and the entire fieldwork team for their hard work during the two fieldwork phases. An earlier version of this paper was presented at the Migrating Out Of Poverty Conference in March 2017, and the authors acknowledge the comments and feedback received at the session which, together with the reviewers' comments, have helped to strengthen the manuscript.

Contributors This study was conducted as part of the Study of Work in Freedom Transnational Evaluation for which CZ and LK are co-Pls. This analysis is part of JM's doctoral research. LK, CZ and JM were involved in the study conception and design. JM, LK, CZ and BS designed the data collection tool. JM managed the data collection; cleaned, analysed and interpreted the data; and wrote the first draft of the manuscript. TA provided statistical advice. All authors contributed to interpretation, critically reviewed and approved the final manuscript.

Funding This project was supported by the UK Department for International Development (GB-1-203857).

Competing interests None declared.

Patient consent There were no patients involved in the study. However all study participants signed a consent form prior to data collection.

Ethics approval LSHTM Ethics Committee and the Nepal Health Research Council. Provenance and peer review Not commissioned; externally peer reviewed. Data sharing statement No additional data are available.

Open Access This is an Open Access article distributed in accordance with the Creative Commons Attribution Non Commercial (CC BY-NC 4.0) license, which permits others to distribute, remix, adapt, build upon this work non-commercially, and license their derivative works on different terms, provided the original work is 
properly cited and the use is non-commercial. See: http://creativecommons.org/ licenses/by-nc/4.0/

(C) Article author(s) (or their employer(s) unless otherwise stated in the text of the article) 2017. All rights reserved. No commercial use is permitted unless otherwise expressly granted.

\section{REFERENCES}

1. Human Development Report 2015. Work for Human Development. New York, NY, USA: UNDP, 2015.

2. Chuang J. Beyond a Snapshot: preventing human trafficking in the global economy. Indiana Journal of Global Legal Studies 2006;13:137-63.

3. Wickramasekera P. Asian labour migration: issues and challenges in an era of globalization. Geneva: ILO, 2002.

4. Adhikari J, Hobley M. Everyone is leaving - who will sow our fields? the effects of migration from Khotang district to the Gulf and Malaysia. Kathmandu, Nepal: SDC, 2011.

5. McLeman R, Smit B. Migration as an adaptation to climate Change. Clim Change 2006;76:31-53.

6. The Asia Foundation. Labour migration trends and patterns. 2013. Bangladesh, India, and Nepal.

7. World Bank. Nepal development update. remittances at risk, 2016.

8. Environmental Justice Foundation. Sold to the sea. human trafficking in Thailand's fishing industry. London: Environmental Justice Foundation, 2013.

9. Paoletti S, Taylor-Nicholson E, Sijapati B, et al. Migrant workers access to justice at home. Nepal, 2014.

10. ILO. Hard to see, harder to count. survey guidelines to estimate forced labour of adults and children. Geneva: ILO, 2012.

11. Andrees B, van der Linden MNJ. Designing trafficking research from a labour market perspective: the ILO experience. International Migration. Geneva, Switzerland: International Organization for Migration, 2005.

12. Turner-Moss E, Zimmerman C, Howard LM, et al. Labour exploitation and health: a case series of men and women seeking post-trafficking services. J Immigr Minor Health 2014;16:473-80.

13. Al-Maskari F, Shah SM, Al-Sharhan R, et al. Prevalence of depression and suicidal behaviors among male migrant workers in United Arab Emirates. J Immigr Minor Health 2011;13:1027-32.

14. Weitzer R. New Directions in Research on human trafficking. Ann Am Acad Pol Soc Sci 2014;653:6-24.

15. Omar Mahmoud T, Trebesch C. The economics of human trafficking and labour migration: micro-evidence from Eastern Europe. J Comp Econ 2010;38:173-88.

16. Makisaka M. Human trafficking: a brief overview. Washington, USA: World Bank, 2009.

17. Jordan A. Slavery, forced labor, debt bondage, and human trafficking: from conceptional confusion to targeted solutions. Program on Human Trafficking and Forced Labor, Center forHuman Rights and Humanitarian Law. Washington, USA: American University of Washington College of Law, 2011.

18. Piper N, Segrave M, Napier-Moore R. Editorial: what's in a name? distinguishing forced labour, trafficking and slavery. Anti-Trafficking Review 2015:1-9.

19. Government of Nepal. National Population and Housing Census 2011 National Report. Kathmandu, Nepal: National Planning Commission Secretariat, 2012.

20. Government of Nepal. Labour Migration for Employment. a Status Report for Nepal 2014/2015. Kathmandu, Nepal: Ministry of Labour and Employment, 2016.

21. Sharma JR. Practices of Male Labor Migration from the Hills of Nepal to India in Development Discourses: which pathology? Gend Technol Dev 2008;12:303-23.

22. Bruslé T. Choosing a destination and work. migration strategies of nepalese workers in Uttarakhand, Northern India. Mountain Research and Development 2008;28:240-7.
23. Libois F. Households in times of war: adaptation strategies during the Nepal civil war: Namur, Belgium Centre for Research in the Economics of Development (CRED), 2016. Contract No: 2016/03.

24. Williams NE. How community organizations moderate the effect of armed conflict on migration in Nepal. Popul Stud 2013;67:353-69.

25. Bohra P, Massey DS. Processes of internal and international migration from Chitwan, Nepal. Int Migr Rev 2009;43:621-51.

26. Lokshin M, Bontch-Osmolovski M, Glinskaya E. Work-related migration and poverty reduction in Nepal. In: Murrugarra E, Larrison J, Sasin M, eds. Migration and poverty toward better opportunities for the poor. Washington, DC, USA: The World Bank, 2011.

27. Kansakar VBS. Nepal-India open border: Prospects, problems and challenges: Inst. of Foreign Affairs, 2002.

28. ILO. Socioeconomic and labour market trends. A nepalese case. Sanepa, Kathmandu: ILO, 2009.

29. Amnesty International A. False promises. exploitation and forced labour of nepalese migrant workers. London, UK: Amnesty International, 2011.

30. Wright D. Forced labour, trafficking and migration of women in South Asia: UNEAC Asia Papers, 2008.

31. O'Neill T. Anti-Child Labour Rhetoric, Child Protection and Young Carpet Weavers in Kathmandu, Nepal. $J$ Youth Stud 2003;6:413-31.

32. Kumar KCB, Subedi G, Suwal GR. Forced labour of adults and children in the agriculture sector of Nepal. focusing on HaruwaCharuwa in Eastern Tarai and Haliya in Far Western Hills. Kathmandu: ILO Country Office for Nepal, 2013.

33. Giri BR. The bonded labour system in Nepal: musahar and Tharu communities' assessments of the Haliya and Kamaiya labour contracts. Journal of Alternative Perspectives in the Social Sciences 2012;4:518-51.

34. Verité. Forced labor in the production of electronic goods in Malaysia. A comprehensive study of scope and characteristics: Verite, 2014

35. Auwal MA. Ending the exploitation of migrant workers in the Gulf. The Fletcher Forum of World Affairs 2010;34:87-108.

36. Anthony B, Kimball Penrose J, Jakiel S. The typology of modern slavery. Defining sex and labor trafficking in the United States. Washington, DC, USA: Polaris, 2017.

37. Verité. Labor brokerage and trafficking of nepali migrant workers. Amherst, MA, USA: Verité, 2012.

38. Kern A, Muller-Boker $U$. The middle space of migration: a case study on brokerage and recruitment agencies in Nepal. Geoforum 2015;65:158-69.

39. Government of Nepal. Foreign Employment Act, 2064 (2007) Kathmandu, Nepal: ministry of Labour and Employment, Deparment of Foreign Employment. 2007. http://www.dofe.gov.np/uploads/ cmsfiles/file/foreign-employment-act_20120420110111.pdf (10 Aug 2014).

40. Government of Nepal. The Foreign Employment Rules, 2064. Kathmandu, Nepal, 2008.

41. International Organization for Migration. Labour migration from Colombo Processprocess countries Good practices, challenges and way forward. 2011

42. Andrees B. Forced labour and trafficking in Europe: how people are trapped in, live through and come out. Geneva, Switzerland: ILO, 2008.

43. Nepal Human Development Report 2014. Beyond Georgraphy, unlocking human potential. Kathmandu, Nepal: National Planning Commission, UNDP, 2014

44. Benach J, Muntaner C. Precarious employment and health: developing a research agenda. $J$ Epidemiol Community Health 2007;61:276-7.

45. ILO. ILO expert workshop on measuring modern slavery. Geneva, Switzerland: ILO, 2015.

46. Skrivankova K. Between decent work and forced labour examining the continuum of exploitation. York, UK: Joseph Rowntree Foundation, 2010. 